\title{
POR CORRESPONDÊNCIA E PELA INTERNET: HISTÓRIA DA EDUCAÇÃO PROFISSIONAL A DISTÂNCIA NO BRASIL ${ }^{1}$
}

\author{
BY MAIL AND THROUGH THE INTERNET: THE HISTORY OF VOCATIONAL \\ DISTANCE EDUCATION IN BRAZIL \\ POR CORRESPONDENCIA Y POR INTERNET: HISTORIA DE LA FORMACIÓN \\ PROFESIONAL A DISTANCIA EN BRASIL
}

\author{
Fernando Roberto Amorim Souza* \\ Carmen Mazepa Ballão** \\ Eduardo Fofonca** * \\ Irineu Mario Colombo****
}

\section{* Mestre em Gestão e Avaliação da Educação Pública pela Universidade Federal de Juiz de Fora (UFJF). Professor do Instituto Federal do Paraná (IFPR). Segundo Líder do Grupo de Pesquisas Educação a Distância e Tecnologias Digitais. Curitiba, Paraná, Brasil. \\ E-mail: fernandoamorim.df@gmail.com}

** Doutora em Geociências e Meio Ambiente pela Universidade Estadual Paulista "Júlio de Mesquita Filho” (Unesp). Realizou estágio Pós-doutoral em Educação pela Universidade Federal do Paraná (UFPR). Professora do Instituto Federal do Paraná (IFPR). Primeira Líder do Grupo de Pesquisa Educação, Meio Ambiente e Tecnologia. Curitiba, Paraná, Brasil. E-mail: carmen.ballao@ifpr.edu.br

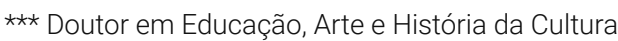
pela Universidade Presbiteriana Mackenzie, SP. Realizou estágio pós-doutoral em Educação da Universidade do Estado de Santa Catarina (UDESC) Professor do Mestrado Profissional em Educação: Teoria e Prática de Ensino da Universidade Federal do Paraná. Coordenador da Editora IFPR. Líder do Grupo de Pesquisas Educação a Distância e Tecnologias Digitais. Curitiba, Paraná, Brasil. E-mail: eduardofofonca@gmail.com

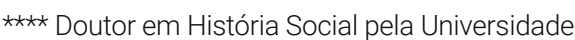
de Brasília (UnB). Realizou estágio Pós-doutoral em Educação pela UFPR. Professor do Instituto Federal do Paraná. Segundo Líder do Grupo de Pesquisa Educação, Meio Ambiente e Tecnologia. Curitiba, Paraná, Brasil. E-mail: colombo@ifpr.edu.br Recebido para publicação: 19.4.2018 Aprovado em: 16.8.2018

\section{Resumo}

O objetivo é destacar aspectos históricos da educação profissional brasileira na modalidade de Educação a Distância e delinear o surgimento recente da Rede e-Tec Brasil e sua institucionalização como política educacional. Analisa-se o desenvolvimento da modalidade a distância com a experiência em outros países e o desenvolvimento da educação profissional presencial nacional. A pesquisa revela que a história da educação profissional está vinculada à modalidade a distância e é uma prática educacional que está em expansão no Brasil.

Palavras-chave: Educação a Distância. Educação Profissional. História da Educação Brasileira.

\section{Abstract}

The objective is to highlight historical aspects of Brazilian vocational education in the modality of Distance Education and to outline the recent emergence of the e-Tec Brazil Network and its institutionalization as an educational policy. The text analyses the development of the distance modality with the experience in other countries and the development of national classroom vocational education. This research reveals that the history of vocational education is linked to the distance modality and is an educational practice that is on the rise in Brazil.

Keywords: Distance Education. Vocational Education. History of Brazilian Education. 


\section{Resumen}

El objetivo es destacar aspectos históricos de la formación profesional brasileña en la modalidad de Educación a Distancia y delinear el reciente surgimiento de la Red e-Tec Brasil y su institucionalización como política educativa. Se analiza el desarrollo de la modalidad a distancia con experiencia en otros países y el desarrollo de la formación profesional presencial nacional. La investigación revela que la historia de la formación profesional está vinculada a la modalidad a distancia y es una práctica educativa que se encuentra en expansión en Brasil.

Palabras clave: Educación a distancia. Formación Profesional. Historia de la Educación Brasileña.

\section{Introdução}

Compreender a história da Educação Profissional sempre foi um desafio para os pesquisadores que buscam o conhecimento necessário para analisar a elaboração e implementação de políticas públicas e práticas educativas no campo da Educação. No Brasil, a Educação Profissional vem sendo ofertada desde o período colonial. Pode-se destacar que muitas leis, decretos e portarias possibilitaram a implementação de diversas políticas públicas relacionadas à oferta de cursos profissionais, contudo, o número de vagas nunca foi suficiente para suprir a demanda de alunos que necessitam dessa formação para o mundo do trabalho.

Desse modo, torna-se relevante que há aproximadamente uma década, o Governo Federal tem demonstrado grande interesse em preencher a lacuna na formação de profissionais de nível técnico, deixada como legado pela política neoliberal adotada pelo país na última década do século 20.

Em 2007 e 2008, respectivamente, foram implementadas duas importantes políticas públicas voltadas à formação profissional: a criação da Escola Técnica Aberta do Brasil (e-Tec Brasil)' , com o objetivo de ampliar e democratizar a formação técnica e tecnológica por meio da Educação a Distância (EAD), ofertada por instituições públicas; e a ampliação da Rede Federal de Educação Profissional, Científica e Tecnológica, por meio da criação dos Institutos Federais, voltados principalmente para a oferta de cursos técnicos. Nesse sentido, foram criadas mais de 450 unidades de ensino técnico com a oferta de mais de 400 mil vagas; contudo, não foi suficiente para atender tal demanda. Sendo assim, o Governo passou a incentivar os Institutos Federais a ofertarem a Educação Profissional na modalidade EAD, financiando cursos técnicos nesta modalidade de ensino por meio do e-Tec Brasil.

A legislação brasileira define a EAD como modalidade de educação escolar, ou seja, uma forma diferenciada de ofertar a educação, atendendo às características do público e com as especificidades didático-pedagógicas para tal (BRASIL, 1996). 
Será que essa prática educativa aponta para um caminho mais curto e menos dispendioso em termos de recursos financeiros com a mesma qualidade do ensino presencial, de tal forma que mereça ter políticas públicas específicas voltadas para ela? Quais foram as principais políticas públicas voltadas à EAD implementadas no Brasil? Estas e outras perguntas serão respondidas no desenvolvimento deste artigo que busca revelar o histórico da educação profissional no Brasil na modalidade EAD.

\section{Histórico da educação profissional presencial no Brasil}

Nos dois primeiros séculos após a colonização, a educação profissional no Brasil se restringia aos pobres, sendo os principais lugares de aprendizagem as Corporações de Ofícios, a Casa-grande dos senhores de engenho, as Casas de Fundição de Moedas e os centros de aprendizagem de ofícios da Marinha.

Com a Independência, logo veio a extinção das Corporações de Ofícios e pouco depois a descentralização do ensino, que resultou na oferta do ensino primário e secundário como responsabilidade das Províncias (GARCIA, 2010, p. 4).

\section{Quais foram}

as principais

políticas

públicas

voltadlas à EAD implementadas no Brasil?
Em 1856, foi criado o primeiro liceu denominado Liceu de Artes e Ofícios do Rio de Janeiro, que serviu de modelo para a criação de outros em diversos estados brasileiros. Era de iniciativa privada, mantido principalmente pela elite burocrática e econômica, mas recebia subvenções oficiais (BIELINSKI, 2009).

No período republicano, além da continuidade dos liceus, ganharam lugar iniciativas públicas de oferta de cursos profissionalizantes, como as escolas profissionais de Campos, Petrópolis, Niterói e Paraíba do Sul, todas no estado do Rio de Janeiro, criadas por Nilo Peçanha. Sua contribuição não se restringiu ao Rio de Janeiro, pois quando esteve na Presidência da República, promoveu a institucionalização da Rede Federal de Educação Profissional e Tecnológica, ao criar 19 Escolas de Artífices, em diferentes estados do país (BRASIL, 2015a, p.2).

A criação das Escolas de Aprendizes Artífices não significou uma integração do trabalho com a educação, pois esta era de base teórica e intelectualista, voltada para a formação dos ricos, enquanto a formação profissional era de base prática, e sua pouca oferta, voltada para os pobres (GONÇALVES, 2005, p. 2).

No início de 1937, foi publicada a Lei n. 378, pela qual as Escolas de Aprendizes Artífices foram transformadas em liceus, para o ensino profissional de todos os ramos e graus, mas continuando a ser destinados aos mais pobres, confinados no ensino primário e profissional. Como nota Batista e Lima (2011), nessa época, a educação da maioria da população não proporcionava acesso ao ensino superior.

Segundo Faria (2010), depois da Constituição de 1937, que em seu artigo 128 tornava livre a oferta de ensino por instituições e associações particulares, somada 
à redução dos impostos sobre o papel e a necessidade urgente de mão de obra qualificada para o recente crescimento industrial, duas iniciativas privadas inauguraram a oferta regular de educação a distância no Brasil, por meio de postagem de material pelo correio: o Instituto Monitor e o Instituto Universal Brasileiro.

A partir de 1942, passou a vigorar uma série de decretos-leis conhecida como "Reforma Capanema" ou "Leis Orgânicas de Ensino", com base nos quais todo ensino profissional brasileiro passou a ter regulamentação (GARCIA, 2000, p. 7).

A Lei Orgânica do Ensino Industrial, de 1942, seguida da Lei Orgânica do Ensino Comercial, em 1943, e por último, a Lei Orgânica do Ensino Agrícola, em 1946, colocaram o ensino técnico profissional como nível secundário e o ingresso nas escolas passou a depender de exames de admissão. Os cursos foram divididos em dois ciclos. $01^{\circ}$ ciclo, denominado curso básico, compreendia quatro anos de estudos após o ensino primário. $02^{\circ}$ ciclo, o curso técnico, com duração de 3 ou 4 anos, passou a ser frequentado pelos egressos do curso básico. Os estudantes que concluíssem o $2^{\circ}$ ciclo poderiam ser admitidos no ensino superior, desde que o curso pretendido tivesse relação direta com o curso comercial finalizado (BRASIL, 1942).

Em sintonia com as Leis Orgânicas da Educação Profissional, foi publicado o Decreto-lei n. 4.127/42, que estabeleceu as bases de organização da Rede Federal de estabelecimentos de ensino industrial, instituindo quatro tipos de escolas federais: as escolas técnicas, para ensino de $1^{\circ} \mathrm{e} 2^{\circ}$ ciclos; as escolas industriais, para ensino de $1^{\circ}$ ciclo; as escolas artesanais, para cursos de curta duração; e, as escolas de aprendizagem, para os trabalhadores das indústrias.

A expansão das escolas técnicas federais não foi suficiente para atender à demanda da indústria por qualificação profissional técnica, que era um dever estabelecido pela Constituição do Estado Novo de 1937 (BRASIL, 1937). Por iniciativa do Governo, criou-se, então, em 1942, o Serviço Nacional de Aprendizagem Industrial (Senai), em parceria com a Confederação Nacional da Indústria (CNI). O mesmo ocorreu com a Confederação Nacional do Comércio (CNC), que, em 1946, criou o Serviço Nacional de Aprendizagem Comercial (Senac).

Em 1959, a Lei n. 3.552 transformou as escolas federais em autarquias, ganhando autonomia administrativa e pedagógica. No entanto, continuavam vedando ao aluno progressão para cursos superiores, exceto no seu ramo profissional.

A Lei de Diretrizes e Bases da Educação Nacional (LDB) de 1961 aproximou o ensino profissional do ensino acadêmico, contudo, na prática, a formação profissional continuava desvalorizada socialmente.

Na década de 1970, com a aceleração do crescimento econômico, houve uma forte expansão de cursos profissionais. Em 1971, o Governo publicou a Lei n. 5.692, reformando a LDB na parte que antecede o ensino superior, criando o ensino de $1^{\circ}$ e $2^{\circ}$ graus. Com essa norma, todas as escolas secundárias do Brasil estavam obrigadas a ofertar cursos técnicos. 
Em 1978, surgiram os três primeiros Centros Federais de Educação Tecnológica (Cefets), que tinham como objetivo, além dos cursos técnicos, formar engenheiros de operação e tecnólogos.

Com a aprovação da LDB de 1996 (Lei n. 9.394), a educação profissional ganhou notoriedade no Brasil. Contudo, o texto da lei não definiu competências e responsabilidades sobre ela. Segundo Saviani (1997, p. 216), era intenção do Governo que não houvesse comprometimento do Ministério da Educação com as escolas técnicas federais, as quais, no entanto, eram uma experiência bem-sucedida de organização do nível médio que articula formação geral científica com o trabalho produtivo.

Esse descompromisso estava alicerçado em uma perspectiva neoliberal de retrair a oferta de educação profissional pelo poder público, a fim de criar terreno fértil para a preponderância da iniciativa privada (PACHECO, 2012).

As ações foram em quatro frentes: 1) restrição orçamentária para os cursos técnicos públicos; 2) reforço da dualidade e flexibilização para oferta, por meio de regulamentação da LDB; 3) empréstimo para a iniciativa privada constituir suas próprias escolas de cursos de curta duração; e, 4) impedimento legal de surgimentos de novas escolas públicas federais.

Segundo Tavares (2012, p. 11), com as quatro frentes houve um congelamento na criação de vagas e escolas públicas para essa modalidade educacional. Somente a partir de 2004 ocorreu a retomada da oferta de cursos técnicos federais motivados pelos investimentos financeiros governamentais.

A publicação do Decreto n. 5.154/04 representou uma nova concepção para a Educação Profissional e Tecnológica (EPT), segundo o qual esta passou a ter possibilidade de integração ao ensino médio, ampliando assim a perspectiva de participação do Governo na oferta desse nível educacional e permitindo que todos os alunos de escolas públicas ou privadas pudessem frequentar o ensino médio e o ensino técnico ao mesmo tempo, na mesma grade curricular e na mesma escola.

Em 2005, foi sancionada a Lei n. 11.195/2005, que permitiu a expansão da educação profissional brasileira, sendo criadas 214 novas escolas técnicas entre 2005 e 2007 (TAVARES, 2012).

Já o Decreto n. 5.840/06 criou o Programa Nacional de Integração da Educação Profissional com a Educação Básica na Modalidade de Educação de Jovens e Adultos (Proeja), contemplando ensino fundamental, médio e educação indígena (BRASIL, 2015a, p. 6).

Em 2007, o Ministério da Educação lançou o Programa Brasil Profissionalizado, com o objetivo de "financiamento de obras de infraestrutura, desenvolvimento de gestão, práticas pedagógicas e formação de professores" nas redes estaduais de educação, visando a retomada da oferta em articulação nacional, sendo o programa articulado com novas políticas, como: o Catálogo Nacional dos Cursos Técnicos; a nova lei de estágios; o programa de profissionalização para jovens e adultos; e o ensino técnico a distância (COLOMBO, 2008, p. 8). 
Em 2008, além da publicação da Lei n. 11.741, que alterou a LDB acrescentando ao seu corpo a Seção IV-A do Capítulo II, o qual ressalta que os cursos profissionalizantes fazem parte da educação básica, o Ministério da Educação reorganizou a Rede Federal de Educação Profissional, ao criar 38 Institutos Federais de Educação, Ciência e Tecnologia com base no potencial instalado e congregando antigas escolas técnicas federais, Cefets, Escolas Técnicas vinculadas a Universidades Federais, Escolas Agrotécnicas Federais e o Colégio Pedro II.

Os Institutos Federais passaram a agregar novas características na oferta de educação profissional. A expansão de novos campi ocorreu principalmente para o Oeste do país, em locais de pouco ou nenhuma oferta educacional. Passaram a ter políticas inclusivas e a ofertar, além do ensino, também a pesquisa e a extensão para os alunos do ensino médio técnico e uma maior integração entre formação geral e formação técnica e tecnológica. Passaram a verticalizar a oferta da profissionalização começando por cursos de Formação Inicial e Continuada $(\mathrm{FIC})^{2}$, passando pelos cursos do Proeja, pelos cursos técnicos integrados ao ensino médio, pelos cursos superiores de graduação ou de tecnologia, por mestrado profissional e até doutorado.

Em 2011, foi lançado o Programa Nacional de Acesso ao Ensino Técnico e Emprego (Pronatec) com a finalidade de interiorizar, expandir e democratizar a oferta de educação profissional no Brasil.

Além dos cursos regulares, mantidos com recursos orçamentários ordinários do MEC, o Pronatec visava financiar outros cursos na sua própria rede, mas também nas redes de educação profissional e tecnológica estaduais, distritais e municipais, bem como nos Serviços Sociais Autônomos, o chamado "Sistema S", que engloba, além do Senac, instituições como o Serviço Nacional de Aprendizagem Industrial (Senai), o Serviço Nacional de Aprendizagem do Transporte (Senat) e o Serviço Nacional de Aprendizagem Rural (Senar) (BRASIL, 2015b).

Além disso, torna-se importante destacar que a reboque do Telecurso $2^{\circ} \mathrm{Grau}$, o surgimento do Telecurso 2000 Profissionalizante, iniciativa que envolveu Fundação Padre Anchieta (mantenedora da TV Cultura), Fundação Roberto Marinho ${ }^{3}$ e Federação das Indústrias do Estado de São Paulo (Fiesp), teve papel fundamental para que a educação profissional a distância ganhasse popularidade, dada a ampla cobertura, penetração e capilaridade expandidas pelo uso da TV de recepção aberta no Brasil.

Apesar de todos esses avanços, a educação profissional ainda é uma modalidade inacessível a muitos jovens e adultos, pois levar a educação básica presencial para este vasto país sempre foi um desafio. A tarefa é ainda mais difícil no caso da educação profissional, que exige altos investimentos em tecnologia e infraestrutura escolar, tais como materiais didáticos e laboratórios específicos. Diante desse cenário, a Educação Profissional a Distância surge como meio facilitador para a aceleração da oferta de cursos técnicos no Brasil e um meio de assegurar o acesso de todos. 


\section{Histórico da educação profissional a distância em outros países}

A Educação a Distância evoluiu muito no decorrer do tempo, passando da correspondência via correios às mídias modernas. É evidente que ganhou mais espaço e notoriedade com o desenvolvimento e a incorporação das novas tecnologias digitais. Segundo Faria (2010), a EAD acompanhou a evolução das tecnologias de comunicação que lhe dão suporte, sem necessariamente ter implicado evolução pedagógica, mas notoriamente com um avanço qualitativo e quantitativo.

A primeira oferta em EAD foi um curso profissional por correspondência. Os Estados Unidos e a Suécia foram os pioneiros nessa modalidade de ensino profissional. Em 1728, um professor de taquigrafia anunciou na Gazeta de Boston sua disposição de ensinar esta técnica com o envio semanal de materiais para ensino e receber tutoria por correspondência (FARIA, 2010, p. 135).

Em 1833, foi criado um curso de contabilidade na Suécia, pelo Instituto Liber Hermods. Nesse mesmo ano, um anúncio em inglês em um periódico sueco, Lunds Weckoblad, revelou uma oportunidade de estudar composição por meio de postagens.

Em 1840, o inglês Isaac Pitman criou um sistema de ensino de taquigrafia na base de fichas que enviava para seus alunos via intercâmbio postal. Essa experiência comprovada de interação contínua entre aluno e professor a distância é considerada por muitos o verdadeiro marco do início da EAD.

A Educação

a Distância evoluiu muito

no decorrer

do tempo,

passando da

correspondência

via correios

às mídias

modernas
Após Pitman, outros exemplos bem-sucedidos de experiências em EAD podem ser mencionados, como Thomas J. Foster que, em 1891, iniciou, na Pensilvânia (EUA), um curso sobre medidas de segurança no trabalho de mineração; e o sueco Hans Hermod, diretor de uma escola que ministrava cursos de línguas e comerciais e lançou, em 1898, o primeiro curso por correspondência na área de Contabilidade.

O rádio, desde suas primeiras transmissões comerciais em 1907, em Nova York, foi imediatamente incorporado ao processo educacional a distância. Iniciava-se a segunda geração desse tipo de modalidade de ensino por aquele meio, que seria seguido pela televisão.

A oferta da EAD foi se ampliando. Na década de 1930, diversas universidades norte-americanas começaram a ofertar cursos a distância. Na década de 60, apesar do preconceito sofrido pelas universidades a distância, um marco para a história da EAD foi a criação da Universidade Aberta da Grã-Bretanha (Open University), que em 1969, trouxe a utilização de novos meios, como a televisão e os cursos intensivos em períodos de recesso da educação convencional. Essa experiência acabou se transformando em um modelo de EAD, gerando muita competitividade nos cursos presenciais. Na mesma década, foram 
criadas mais duas importantes universidades na modalidade EAD: a Universidade Aberta da Venezuela e a Universidade Estadual a Distância da Costa Rica (FIALA et al., 2008, p. 2).

Vale lembrar também que, em 1930, com a chegada da transmissão televisiva, que era assistida na Alemanha em salas especiais, o termo educação a distância passou a substituir o estudo por correspondência, e o seu uso foi popularizado pela Open University, com a oferta de seus cursos a partir de 1971.

Contudo, o uso da correspondência postal estreou a educação a distância preenchendo as lacunas dos sistemas de ensino formal quanto à profissionalização e continua, até os dias atuais, mostrando que é uma ferramenta poderosa e aliada das outras mídias (GIUSTA; FRANCO, 2003).

Das correspondências às mais modernas tecnologias de informação e comunicação, a EAD evoluiu e já são mais de dois séculos de experiências que permitem afirmar que essa modalidade de ensino vem contribuindo significativamente para a formação profissional em diversos países, assim como no Brasil.

\section{Histórico da Educação Profissional a Distância no Brasil}

No Brasil, a educação profissional a distância foi iniciada em 1891 com a oferta de um curso de datilografia por correspondência, anunciado nos classificados do Jornal do Brasil. Desde então, outras experiências também foram exitosas, por meio de correios, rádio, televisão, satélites e internet, contribuindo para o avanço dessa modalidade de ensino no país.

Com o avanço das tecnologias de informação e comunicação, a EAD deu um salto qualitativo e quantitativo em sua oferta, principalmente, a partir do uso da internet na transmissão das aulas, visto que o aluno, em qualquer lugar do país, poderia receber uma qualificação profissional a distância. Contudo, é importante resgatar o longo trajeto histórico do uso das tecnologias que vêm permitindo a formação técnica no Brasil durante mais de um século. Embora iniciada no fim do século 19, somente em meados do século 20 os avanços nessa modalidade de ensino se tornaram mais visíveis.

Entre as décadas de 1920 e 1950, ocorreram importantes avanços que se tornaram marcos na história da EAD no Brasil, sendo que alguns deles já apresentavam um cunho de formação profissional. Por ordem cronológica, os que mais se destacaram foram: a fundação da Rádio Sociedade do Rio de Janeiro, em 1923; a criação do Serviço de Radiodifusão Educativa, pelo Ministério da Educação e Saúde, em 1937; a fundação do Instituto Rádio Monitor (1939) e o Instituto Universal Brasileiro (1941). Em 1946, o SENAC iniciou suas atividades, criando, em 1950, a Universidade do Ar, cobrindo localidades fluminenses e paulistas.

Pode-se considerar que a primeira escola brasileira de educação profissional a distância com estrutura e consistência pedagógica foi o Instituto Rádio Monitor, im- 
plantada pelo imigrante húngaro Nicolás Goldberg, que utilizou sua experiência em eletrônica e implantou o primeiro curso técnico por correspondência no país. A metodologia consistia no envio de apostilas e um kit de componentes eletrônicos aos alunos, enquanto a interação se dava por correspondências enviadas pelos correios.

Em 1941, derivada da experiência do Instituto Rádio Monitor, um de seus antigos sócios montou o Instituto Universal Brasileiro (IUB), com "cursos informais" de datilografia, taquigrafia, estenografia e eletrônica em rádio (FARIA, 2010, p. 19). As cartilhas e manuais eram produzidos pelo IUB e enviados aos alunos via correio, em seguida, eles devolviam as lições respondidas.

Entre as décadas

de 1950 e 1970, muitos brasileiros

receberam

uma formação

profissional a

distância
Dois fatores induziram o surgimento dessas instituições e tantas outras de ensino profissional a distância. O primeiro foi o artigo 129 da Constituição de 1937, que preconizava o ensino pré-vocacional às classes menos favorecidas, assim como a fundação de institutos de ensino profissional, que poderiam ser de iniciativa dos governos, dos indivíduos ou de associações particulares (BRASIL, 1937). O segundo foi o processo de industrialização pela substituição de importações, com o incremento de equipamentos elétricos e eletrônicos, entre eles, o rádio, que "à época já possuía mais de 50 emissoras" (FARIA, 2010) e necessitava de técnicos para instalação e serviços de reparos nas mais longínquas regiões do país.

Entre as décadas de 1950 e 1970, muitos brasileiros receberam uma formação profissional a distância, devido aos projetos colocados em prática nas décadas anteriores. Um exemplo foi a instalação, em São Paulo, em 1962, da empresa estadunidense Occidental School, especializada em educação por correspondência, que passou a atuar na área da eletrônica, produzindo revistas e cursos.

Vários institutos particulares que promoviam a educação profissional tanto na área da eletrônica quanto datilografia e contabilidade passaram a oferecer cursos de formação escolar geral pós-primário por correspondência. Foi a possibilidade dada pelo artigo 91 do Decreto-lei n. 4.244/1942, a chamada "Reforma Capanema", que permitia aos maiores de 19 anos a obtenção de licença ginasial por ensino realizado particularmente. O mesmo Decreto não mencionava o ensino a distância, mas em seu artigo 69 deixava livre o ensino secundário ministrado pela iniciativa particular. Combinando as possibilidades legais de ambos os artigos, muitas empresas passaram a divulgar cursos por correspondência de formação geral, pois já contavam com boa base metodológica e de estrutura, advindas do ensino profissional a distância.

A década de 1970 foi, especialmente, marcada pela implantação do Projeto Minerva, que embora não seja considerado de educação profissional, foi de grande relevância, pois contribuiu para o aumento da escolarização de brasileiros adultos. Tal projeto utilizou-se do rádio para difusão das aulas. Todas as emissoras do país eram obrigadas a transmitir a sua programação, uma forma encontrada pelo Gover- 
no para garantir o acesso ao ensino para os estudantes que não podiam frequentar a escola no modelo tradicional.

Embora a EAD tenha surgido em 1891, foi somente em 1961 que o governo brasileiro tratou dessa modalidade de ensino como política pública.

Segundo Alves (1994), o marco legal para educação a distância no Brasil ocorreu com a promulgação da primeira LDB, Lei n. 4.024/1961. Em seu artigo 25, parágrafo segundo, destacava que "os cursos supletivos serão ministrados em classes ou mediante utilização de rádio, televisão, correspondência e outros meios de comunicação que permitam alcançar o maior número de alunos" (BRASIL, 1961).

A regulamentação mais detalhada sobre o tema veio em 1971, mas "específica para o ensino supletivo a distância", por ser considerada uma educação de menor qualidade, voltada aos pobres e devido à precariedade dos correios (ZAMLUTTI, 2006).

Os motivos dessa demora podem ser considerados insignificantes e até mesmo discriminatórios, mas se justificam pelo momento político vivenciado pelo país, de regime militar.

Mesmo sem regulamentação, muitos cursos profissionais livres, a distância, foram ofertados no Brasil antes da década de 1970. Tratava-se de uma experiência comprovada de educação a distância por vários motivos, por exemplo, por ser sistemática, por haver interação entre a instituição e os alunos, por se submeter aos controles dos órgãos e Governo, tendo solidez no formato que perdura até os dias atuais.

Desde então, diversas outras instituições têm conquistado relevância social na qualificação profissional a distância. No que diz respeito à educação pública nessa modalidade, a ausência de legislação específica atrasou seu avanço. Foram as instituições privadas que conquistaram espaço, ofertando cursos profissionalizantes considerados livres, sem necessidade de registros formais, devido ao não intervencionismo do poder público.

Entre as décadas de 1970 e 1980, várias iniciativas privadas passaram a ofertar cursos supletivos a distância, por intermédio do uso combinado da televisão, aulas via satélite e conjunto de materiais impressos. Até 1990, a EAD continuava a ser considerada no Brasil uma educação de menor qualidade, voltada para cursos profissionalizantes e escolarização supletiva. Desde então, diversas políticas públicas implementadas culminaram no fortalecimento da EAD no Brasil.

Em 1990, houve uma mobilização no ambiente universitário para que as novas tecnologias fossem usadas para cursos superiores de EAD. Em 1992, foi criada a Universidade Aberta de Brasília (Lei Estadual 303/1992) e, em 1995, Associação Brasileira de Educação a Distância (Abed). Até a aprovação da nova LDB, (Lei n. 9.394/96), as propostas de regulação para EAD referiam-se apenas à educação superior, pelo fato de a educação profissional figurar como parte da educação básica.

A LDB, no seu artigo 80, abriu novos horizontes para essa modalidade em todos os níveis da educação, estabelecendo que "o Poder Público incentivará o desenvol- 
vimento e a veiculação de programas de ensino a distância, em todos os níveis e modalidades de ensino, e de educação continuada".

Apesar disso, os primeiros projetos formais de educação profissional de nível médio somente começaram a ser pensados com a regulamentação do artigo 80 da LDB, a partir da publicação do Decreto n. 5.622/05.

O Decreto n. 5.622/05 foi o marco legal que inaugurou o início da oferta de cursos formais da educação profissional, fortalecendo e incentivando a implantação de cursos técnicos de nível médio subsequente na modalidade a distância. O referido decreto também possibilitou a implantação, por parte do Ministério da Educação, da primeira política pública voltada ao incentivo da oferta de cursos técnicos de nível médio na modalidade a distância pelas instituições de ensino público.

poder público reparou o débito histórico com a educação profissional a distância
O Ministério da Educação, em 2007, por meio do Decreto n. 6.301/07, implantou o Sistema Escola Técnica Aberta do Brasil (e-Tec Brasil), cujo objetivo, descrito em seu artigo primeiro, é o "desenvolvimento da educação profissional técnica na modalidade de educação a distância, com a finalidade de ampliar a oferta e democratizar o acesso a cursos técnicos de nível médio, públicos e gratuitos no País". Portanto, o poder público reparou o débito histórico com a educação profissional a distância.

Por meio do e-Tec Brasil, o governo brasileiro passou a formalizar os procedimentos para a oferta da educação profissional a distância; a promover investimento orçamentário específico; a acompanhar e avaliar os cursos e a incentivar a utilização das novas tecnologias digitais. O programa passou a ser um verdadeiro sistema educacional, atuando em rede, criando padronização mínima e alcançando capilaridade nacional.

A formatação no modelo e-Tec-Brasil, segundo o decreto, segue a mesma configuração atribuída à Universidade Aberta do Brasil (UAB), a única diferenciação consiste no nível de ensino. Cabe ao Ministério da Educação a seleção de instituições de ensino de educação profissional interessadas na oferta de cursos técnicos na modalidade de educação a distância, bem como o credenciamento dos polos de apoio presencial para o apoio técnico e financeiro pelo órgão.

O e-Tec Brasil passou por uma reformulação em 2011 para adequar-se ao Pronatec. O Decreto n. 6.301/07 foi revogado pelo Decreto n. 7.589/2011. O MEC extinguiu o Sistema Escola Técnica Aberta do Brasil e instituiu a Rede e-Tec Brasil ${ }^{4}$. O termo e-Tec Brasil permaneceu por estar popularizado. Mas não foi somente uma alteração de nomenclatura, a principal diferenciação foi a valorização da autonomia pedagógica das instituições de educação profissional e o incentivo ao uso de diferentes metodologias tecnológicas. Essa diferenciação ampliou significativamente o número de instituições no Programa e o número de matrículas cresceu de 28.744 para 75.364, com a recém-criado Rede e-Tec Brasil. 
A Rede e-Tec Brasil é um importante programa de incentivo à educação profissional a distância, com a oferta de vagas públicas e gratuitas. Há, porém, diversas outras iniciativas de oferta de cursos de educação profissional EAD pela iniciativa privada, segundo o Sistema Nacional de Informações da Educação Profissional e Tecnológica (Sistec), contribuindo para a ampliação das oportunidades educacionais e sociais por meio da educação profissional a distância no Brasil.

\section{Considerações finais}

A história da educação profissional a distância aponta para uma tendência de superação dos problemas iniciais, que se referiam, principalmente à qualidade do ensino. Com a evolução das tecnologias de informação e comunicação, a EAD deu um grande salto qualitativo, tornando-se atraente não só para os estudantes, mas também para professores que passaram a dedicar suas carreiras a essa modalidade de ensino.

Percebe-se que, no Brasil, a discriminação da EAD está ficando no passado. Importantes universidades, públicas e privadas, passaram a ofertar educação profissional a distância por reconhecerem nela uma oportunidade de democratizar o acesso a uma educação de qualidade. Tudo isso é consequência das políticas públicas implementadas nas últimas décadas pelo governo brasileiro.

A EAD teve seu início voltado para a profissionalização e, mesmo sendo fruto da iniciativa privada, direcionada aos pobres. Foi absorvida pela universidade, aperfeiçoou-se, adotou novas mídias, ganhou notoriedade e recebeu regulação oficial.

O que se deseja com esta construção histórica é mostrar que é possível a esta modalidade de ensino retornar parcialmente à sua origem, ou seja, preparar profissionais de nível médio a distância, para contribuir com a superação do estigma de ser uma oferta direcionada unicamente aos pobres, deixando de ser focada apenas na produção de mão de obra, para ser um fator de indução ao desenvolvimento nacional.

\section{Nota}

Este estudo é parte de uma análise realizada pelos grupos de pesquisa Educação, Meio Ambiente e Tecnologia, e Educação a Distância e Tecnologias Digitais, ambos vinculados ao Conselho Nacional de Desenvolvimento Científico e Tecnológico (CNPq) e ao Instituto Federal do Paraná (IFPR).

${ }^{2}$ Segundo o Decreto n. 5.154/2004, FIC são cursos para "capacitação, o aperfeiçoamento, a especialização e a atualização de profissionais, em todos os níveis de escolaridade, nas áreas da educação profissional e tecnológica”. Os cursos variam de 160 até 400 horas em mais 644 cursos, segundo o Guia Pronatec de Cursos FIC (BRASIL, 2015b).

${ }^{3}$ Projeto vinculado à Rede Globo de Televisão. 
${ }^{4}$ Lançado em 2007, o sistema Rede e-Tec Brasil visava à oferta da educação profissional e tecnológica a distância com o propósito de ampliar e democratizar o acesso aos cursos técnicos de nível médio, públicos e gratuitos, em regime de colaboração entre União, Estados, Distrito Federal e Municípios.

\section{Referências}

ALVES. J. R. M. A Educação a distância no Brasil: síntese histórica e perspectivas. Rio de Janeiro: Instituto de Pesquisas Avançadas em Educação, 1994.

BATISTA, U. A. D.; LIMA, M. F. Considerações sobre a trajetória histórica da formação profissional no Brasil de 1940 a 1990. Emancipação, Ponta Grossa, v. 11, n. 1, 2011.

BIELINSKI, A. C. O Liceu de Artes e Ofícios: sua história de 1856 a 1906. 19\&20, Rio de Janeiro, v. 4, n. 1, jan. 2009. Disponível em: <http://www.dezenovevinte.net/ ensino_artistico/liceu_alba.htm >. Acesso em: 12 dez. 2016.

BRASIL. Constituição (1988). Constituição dos Estados Unidos do Brasil de 10 de novembro de 1937. Rio de Janeiro: Impr. Nacional, 1937.

BRASIL. Decreto n. 5.622, de 19 de dezembro de 2005. Regulamenta o art. 80 da Lei n. 9.394, de 20 de dezembro de 1996. Diário Oficial da União, Brasília, 20 dez. 2005.

BRASIL. Decreto n. 6.301, de 12 de dezembro de 2007. Institui o Sistema Escola Técnica Aberta do Brasil - eTec Brasil. Diário Oficial da União, Brasília, 13 dez. 2007.

BRASIL. Decreto-lei n. 4.073, de 30 de janeiro de 1942. Coleção das Leis do Brasil, Rio de Janeiro, 31 dez. 1942.

BRASIL. Lei n. 4.024, de 20 de dezembro de 1961. Fixa as Diretrizes e Bases da Educação Nacional. Diário Oficial da União, Rio de Janeiro, 27 dez. 1961.

BRASIL. Lei n. 9.394, de 20 de setembro de 1996. Estabelece as diretrizes e bases da educação nacional. Diário Oficial da União, Brasília, 23 dez. 1966.

BRASIL. Ministério da Educação. Centenário da Rede Federal de Educação Profissional e Tecnológica. [Brasília, DF], 2015a. Disponível em: <http://portal. mec.gov.br/setec/arquivos/centenario/historico_educacao_profissional.pdf>. Acesso em: 12 dez. 2016.

BRASIL. Ministério da Educação. Pronatec. Brasília, DF, [2015b]. Disponível em: <http://pronatec.mec.gov.br/institucional-90037/o-que-e-o-pronatec>. Acesso em: 12 dez. 2015. 
COLOMBO, I. M. Brasil profissionalizado: um programa que sistematiza na prática a educação profissional e tecnológica. [Brasília, DF: Ministério da Educação], 2008. Disponível em: <http://portal.mec.gov.br/setec/arquivos/pdf3/artigos_brasil_ profissionalizado.pdf>. Acesso em: 13 dez. 2017.

FARIA, A. A. O Instituto Universal Brasileiro e a gênese da educação a distância no Brasil. Dissertação (Mestrado em Educação) - Universidade Tuiuti do Paraná, Curitiba, 2010.

FIALA. D. A. de S. et al. Educação a distância na educação profissional e tecnológica: histórico e perspectivas. São Paulo: Centro Paula Souza, 2010. Disponível em: <www.centropaulasouza.sp.gov.br/pos-graduacao/workshop-depos-graduacao-e-pesquisa/anais/2010/Trabalhos/gestao-e-desenvolvimento-daformacao-tecnologica>. Acesso em: 4 nov. 2016.

GARCIA, S. R. de O. 0 fio da história: a gênese da formação profissional no Brasil. [S.I.: s.n., 2000]. Disponível em: <www.educacao.rs.gov.br/dados/ seminariointernacional/sandra_garcia_genese_form_profis.pdf>. Acesso em: 12 dez. 2017.

GIUSTA, A.; FRANCO, I. (Org.). Educação a distância: uma articulação entre a teoria e a prática. Belo Horizonte: Lucinas, 2003.

GONÇALVES, L. C. Imagens e memórias da Escola de Aprendizes Artífices de Campos. [S.I.]: UFF; Campos: Cefet, 2005. Disponível em: <http://www.anped.org. br/reunioes/27/gt02/p024.pdf>. Acesso em: 7 out. 2016.

PACHECO, E. Perspectiva da educação profissional técnica de nível médio: proposta de diretrizes curriculares. São Paulo: Moderna, 2012.

SAVIANI, D. A nova lei de educação: trajetórias, limites e perspectivas. Campinas: Autores Associados, 1997.

TAVARES, M. G. Evolução da rede federal de educação profissional e tecnológica: as etapas históricas da educação profissional no Brasil. Caxias do Sul, 2012. Trabalho apresentado no $9^{\circ}$ Seminário de Pesquisa em Educação da Região Sul.

ZAMLUTTI, M. E. M. Uma análise do surgimento da educação a distância no contexto sócio-político brasileiro do final da década de 30 e início da década de 40. Tese (Doutorado em Educação) - Universidade Estadual de Campinas, Campinas, 2006. 